\title{
Experimental Infection with Bovine Herpesvirus-4 Enhances Atherosclerotic Process in Rabbits
}

\author{
Tsun-Mei Lin, Meei-Jyh Jiang, Hock-Liew Eng, Guey-Yueh Shi, Lin-Chun Lai, \\ Bor-Jang Huang, Kun-Yen Huang, and Hua-Lin Wu
}

From the Departments of Medical Technology (T-ML), Anatomy (M-JJ), Biochemistry (G-YS, L-CL, B-JH, H-LW), and Microbiology and Immunology $(\mathrm{K}-\mathrm{YH})$, Medical College, National Cheng Kung University, Tainan; and the Department of Pathology (H-LE), Chang Gung Memorial Hospital at Kaohsiung, Kaohsiung, Taiwan, Republic of China

SUMMARY: An association of herpesvirus and atherosclerosis has been suggested by seroepidemiologic studies and detection of the virus in arterial tissues. To facilitate the studies of the pathogenic role of herpesvirus in atherosclerosis, we established a rabbit model of atherosclerosis with bovine herpesvirus type-4 (BHV-4). Forty New Zealand White rabbits were randomly divided into six groups. Groups 1, 2, and 3 were inoculated iv with BHV-4 and control Groups 4, 5, and 6 with normal saline. Groups 1 and 4 were fed a regular diet throughout the experiment; Groups 2 and 5 were fed a diet supplemented with $2 \%$ cholesterol for 3 weeks starting at 3 weeks postinoculation; and Groups 3 and 6 with a diet supplemented with $2 \%$ cholesterol for 6 weeks starting at 3 days postinoculation. Extensive atherosclerotic lesions in Groups 2, 3, and 6, and small lesions in two rabbits in Group 1 were observed, but no obvious lesions were observed in Groups 4 and 5. BHV-4 DNA was demonstrated by polymerase chain reaction and liquid hybridization in aortic sections, various tissue samples, and peripheral blood mononuclear cells of all infected rabbits. Our studies demonstrated that BHV-4 can accelerate the atherosclerotic process in rabbits, and that experimental infection of rabbits with BHV-4 can be a useful atherosclerosis model. (Lab Invest 2000, 80:3-11).

$T$ he pathogenesis of atherosclerosis is diverse and involves many factors (Kannel et al, 1976). Many forms of insults may cause arterial injury and initiate a chronic, inflammatory response in the vascular wall (Ross and Glomset, 1976; Ross, 1986; Ross, 1993). The resultant up-regulation of expression and secretion of cytokines and growth factors associated with the activated leukocytes may provoke migration and proliferation of smooth muscle cells and other relative and reparative processes leading to lipid deposition and ultimately atherosclerosis (Campbell and Campbell, 1994; Massy and Keane, 1996). A role for herpesviruses, such as cytomegalovirus (CMV), in atherosclerosis has been suggested in studies with different approaches (Melnick et al, 1993; Nicholson and Hajjar, 1998). Antigens and nucleic acids of CMV have been demonstrated in the smooth muscle cells of carotid artery plaques (Melnick et al, 1983; Petrie et al, 1987). Higher levels of CMV antibody have been correlated to the risk of angiographically diagnosed coronary artery disease (Adam et al, 1987). Recently, a population-based cohort study showed a correlation

Received May 14, 1999.

This work was supported by Grants NSC-86-2314-B006-012 and NSC-87-2316-B006-009 from the National Science Council of the Republic of China.

Address reprint requests to: Dr. Hua-Lin Wu, Department of Biochemistry, Medical College, National Cheng Kung University, Tainan, Taiwan 701 Republic of China. Fax: 8866274 1694; E-mail: halnwu@mail.ncku.edu.tw between the level of CMV antibodies and the degree of carotid intimal-medial thickening, an indication of subclinical atherosclerosis (Nieto et al, 1996). These findings are consistent with the putative causal role of CMV infection in atherosclerotic disease. However, no suitable animal models are available for studying the pathogenic role of human $\mathrm{CMV}$ in atherosclerosis, because human CMV has a narrow host range. Span et al (1992) and Persoons et al (1987) have evaluated a rat model using a rat CMV. They were not able to induce atherosclerotic changes in the immunocompetent rats, although they were able to detect active CMV infection in the injured arteries, but only by immunosuppressing rats (Span et al, 1992; Persoons et al, 1994). On the other hand, herpesviral infection has previously been shown to cause atherosclerosis in chickens. Infection of chickens with an avian herpesvirus, Mareks' disease herpesvirus (MDV), induces atherosclerotic lesions in normo- and hypercholesteromic chickens, whose lesions closely resemble chronic atherosclerosis in human arteries (Fabricant et al, 1978; Minick et al, 1979).

BHV-4 is a ubiquitous virus in cattle (Ludwig, 1983; Thiry et al, 1989). BHV-4 was originally referred to as bovine CMV primarily because its biological properties and growth characteristics in tissue culture closely resemble those of CMV (Storz et al, 1984; Staczek, 1990). However, further studies showed BHV-4 is genetically more closely related to herpesvirus Saimiri and Epstein-Barr virus. Therefore, the virus was reclassified as a member of the subfamily Gammaher- 
pesvirinae (Bublot et al, 1992). Similar to other herpesviruses, BHV-4 establishes a life-long latent infection in cattle after natural infection (Castrucci et al, 1991). Experimental inoculation of both cattle and rabbits with BHV-4 has been shown to produce persistent infection in these animals (Osorio et al, 1982; Osorio and Reed, 1983; Naeem et al, 1990; Naeem et al, 1991). The pathogenic effects of BHV-4 or other herpesviruses on the arteries of rabbits have not been reported, however. In a recent report, we found that bovine endothelial cells were susceptible to infection with $\mathrm{BHV}-4$ and that the virus propagated rapidly in bovine endothelial cell cultures (Lin et al, 1997). We therefore hypothesized that infection of BHV-4 might be one of the contributing factors in the pathogenesis in atherosclerosis. Since rabbits are susceptible to inoculation with $\mathrm{BHV}-4$, we conducted a study to evaluate whether inoculation of rabbits with BHV-4 produces infection of the aorta and induces atherosclerosis. A well-established rabbit atherosclerosis model induced by feeding a high-cholesterol diet was also included to observe the effect of viral infection and the degree of atherosclerotic lesions. The findings from this study are presented in this paper.

\section{Results}

\section{Clinical Observations}

No apparent clinical signs of illness were observed in the infected or control animals during the observation period; this result was consistent with the previous findings (Naeem et al, 1991). All infected rabbits in Groups 1, 2, and 3 developed serum antibody $(>1: 160)$ against BHV-4 detected by enzyme-linked immunosorbent assay (ELISA) at 1 week postinfection. The antibody titer remained positive during the experimental period, whereas no antibody $(<1: 20)$ was detected in the mock-inoculated animals.

\section{Plasma Cholesterol}

The mean concentrations of plasma cholesterol in each group of rabbits are shown in Figure 1. Mean concentrations of plasma cholesterol before feeding cholesterol-supplemented diet were between 34 $\mathrm{mg} / \mathrm{dl}$ and $67 \mathrm{mg} / \mathrm{dl}$, which is within the normal range. Cholesterol levels of the virus-infected and mockinfected groups, Groups 1 and 4, fed a regular diet throughout the experiment, remained at similar basal levels. There was no difference between the two groups. Therefore, plasma cholesterol concentrations were not altered by BHV-4 infection. Hypercholesterolemia was observed in all the rabbits fed the $2 \%$ cholesterol diet. Plasma cholesterol increases of 10fold and 20 -fold were observed in rabbits fed the $2 \%$ cholesterol diet for 3 weeks and 6 weeks, respectively. No significant difference in cholesterol levels was observed between virus- and mock-infected groups fed the $2 \%$ cholesterol diet. These observations suggest that BHV-4 infection did not significantly affect the plasma cholesterol metabolism in either normocholesterolemic or the hypercholesterolemic rabbits.

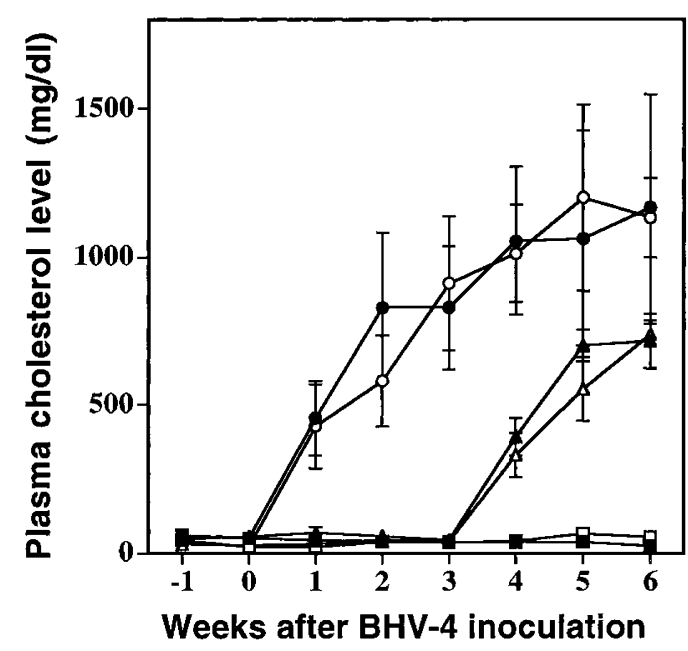

Figure 1.

Plasma cholesterol levels of rabbits. ( $\square$ ): Group $1(n=8)$, rabbits infected with bovine herpesvirus type-4 (BHV-4) and fed a regular diet for 45 days throughout the experimental period. ( $\square$ ): Group $4(n=6)$, mock-infected rabbits fed a regular diet for 45 days. (\): Group $2(n=8)$, rabbits infected with BHV-4 and fed a regular diet for 24 days, then a $2 \%$ cholesterol diet for 21 days. $(\triangle)$ : Group $5(n=5)$, mock-infected rabbits fed a regular diet for 24 days, then a $2 \%$ cholesterol diet for 21 days. (-): Group $3(n=8)$, rabbits infected with BHV-4 and fed a regular diet for 3 days, then a $2 \%$ cholesterol diet for 42 days. (O): Group $6(n=5)$, mock-infected rabbits fed a regular diet for 3 days, then a $2 \%$ cholesterol diet for 42 days. Each point represents the mean $\pm \mathrm{SD}$.

\section{Histopathologic Changes in the Aorta}

The presence of fatty streaks in the aorta was detected by oil red O-staining (Fig. 2). In BHV-4-infected rabbits fed a regular diet (Group 1), small but obvious fatty streaks were observed in thoracic aorta from two rabbits but not from the other six rabbits. No visible fat deposition was detected in thoracic aorta of all the mock-infected controls (Group 4). After 3 weeks of cholesterol feeding, all BHV-4-infected rabbits (Group 2) developed pronounced fatty streaks in the thoracic aorta, particularly in the segments proximal to the aortic arch. In contrast, the mock-infected rabbits (Group 5) showed small and scarce fatty streaks along the branching points, which were not highly visible. In the BHV-4 infected rabbits fed a high-cholesterol diet for 6 weeks (Group 3), severe fatty streaks developed throughout the whole segment of the thoracic aorta. In the mock-infected group (Group 6), the pronounced fatty streaks were observed only in the segments adjacent to the aortic arch. The fatty streaks in the descending thoracic aorta were much milder compared with the virus-infected rabbits (Group 3). These findings were substantiated by morphometric analysis (see below).

Sections of the thoracic aorta from Groups 1, 4, and 5 showed normal histology, which was characterized by a thin intima lined with the endothelium and a thick media (Fig. 3). Extensive fatty lesions were observed in Groups 2, 3, and 6. The difference in histological changes was evident in the virus- and mock-infected groups fed a high-cholesterol diet for 3 weeks (Groups 2 and 5). The intima of the aorta from virus-infected 

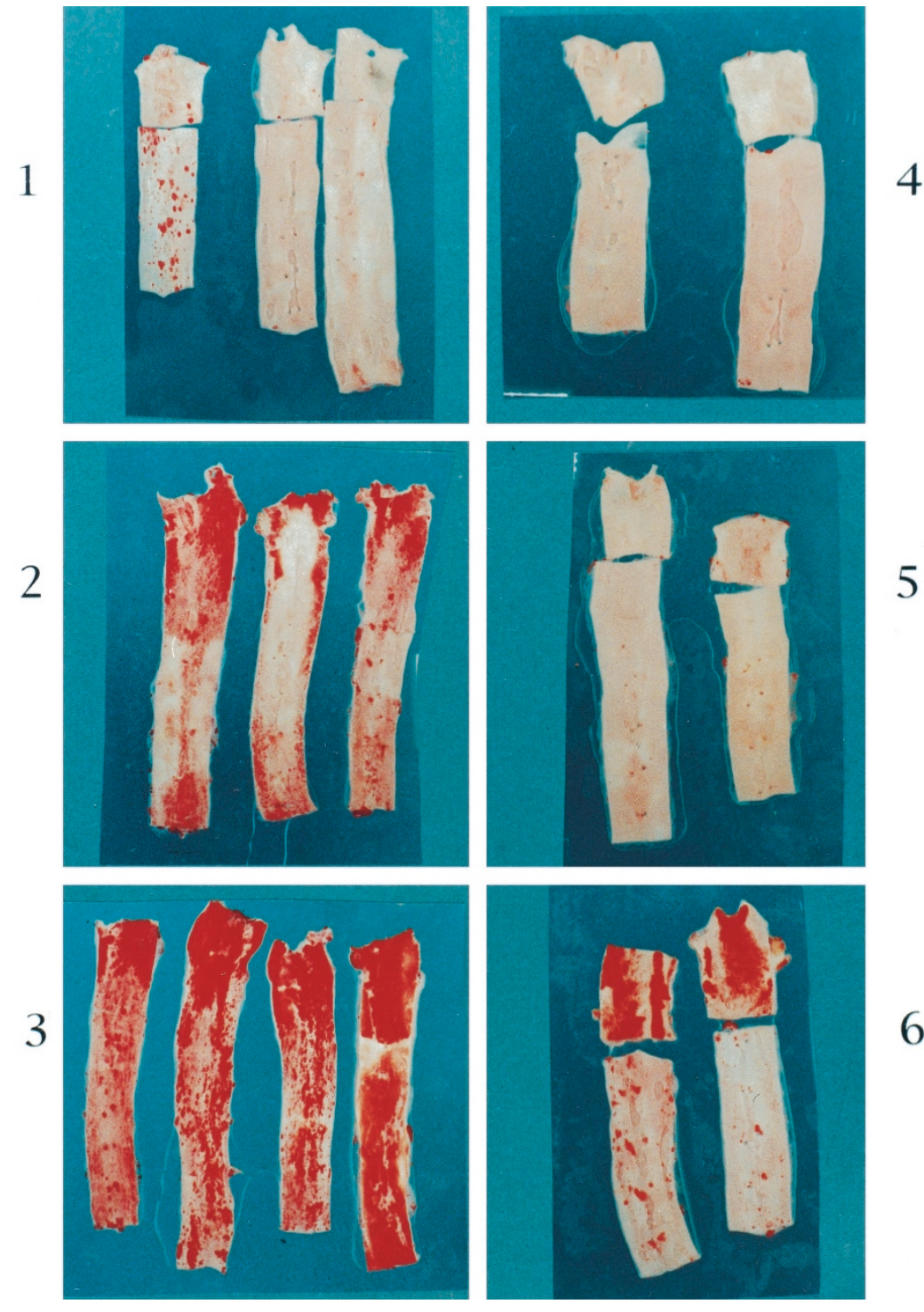

\section{Figure 2.}

The thoracic aorta of rabbits stained with oil red 0 to reveal areas of fatty accumulation. The number on each panel corresponds to the group number in Figure 1 .

rabbits fed a high-cholesterol diet for 3 weeks (Group 2) demonstrated pronounced foam cell formation and an increased intima/media ratio. However, there was virtually no foam cell formation or intimal thickening in mock-infected rabbits fed high-cholesterol diet for 3 weeks (Group 5). It is apparent that BHV-4 infection accelerates the formation of fatty streaks induced by hypercholesterolemia in rabbits. Both virus- and mock-infected groups fed a high-cholesterol diet for 6 weeks developed extensive plaque formation in the thoracic aorta (Groups 3 and 6).

\section{Morphometric Analysis of the Aorta}

The measurements of oil red O-stained area in the thoracic aorta are shown in Figure 4. The mean lesion areas were, respectively, $33.4 \pm 8.2 \%$ and $3.2 \pm 1.0 \%$ in virus- and mock-infected rabbits fed $2 \%$ cholesterol diet for 3 weeks (Groups 2 and 5) ( $p<0.001)$. The mean areas of fatty deposit in animals fed $2 \%$ choles- terol diet for 6 weeks were $70.2 \pm 8.5 \%$ versus $40.5 \pm$ $11.5 \%$ in the virus- and mock-infected rabbits (Groups 3 and 6$)$, respectively $(p<0.01)$. The degree of fatty deposit, expressed as a percentage of total area, was lower in the thoracic aorta of both the virus- and mock-infected groups fed a regular diet, $2.0 \pm 1.4 \%$ for Group 1 and 0\% for Group 4.

\section{Lipid Composition of Thoracic Aorta Segments}

To determine whether virus infection affects lipid types of the arterial wall, the distribution of the major lipids in thoracic aortas of rabbits fed the high-cholesterol dietwas examined by nuclear magnetic resonance $\left({ }^{1} \mathrm{H}\right.$ NMR). As shown in Table 1, in virus-infected rabbits fed $2 \%$ cholesterol diet for 3 weeks, only the cholesterol level increased significantly compared with the mock-infected rabbits $(3.6 \pm 1.7 \mathrm{mg} / \mathrm{g}$ versus $0.4 \pm$ $0.2 \mathrm{mg} / \mathrm{g} ; p<0.05)$. In contrast, after 6 -week cholesterol feeding, the total lipid content and the cholesterol 

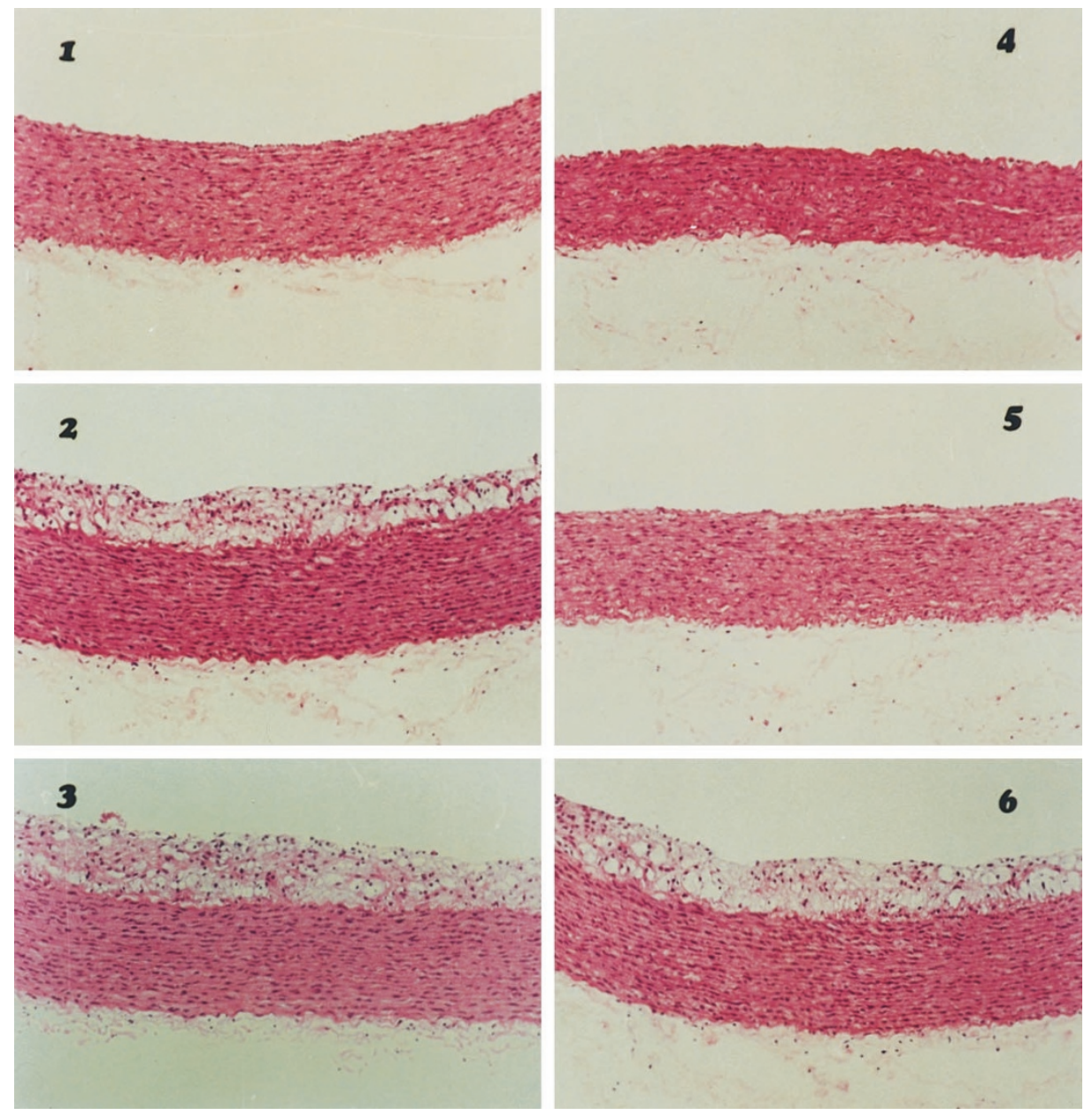

\section{Figure 3.}

Histological findings of atherosclerotic lesions of the thoracic aorta by hematoxylin-eosin stain. The number on each panel corresponds to the group number in Figure 1 .

and cholesterol ester levels all showed significant increase $(p<0.05)$ in virus-infected rabbits (Table 1). In mock-infected rabbits fed a high-cholesterol diet for 3 weeks, triacylglyceride was found to be the major lipid type (35.7 $\pm 19.5 \%$ of total lipid). In virus-infected rabbits fed cholesterol for 3 weeks and in mockinfected rabbits fed cholesterol for 6 weeks, both cholesterol ester and triacylglyceride were the major lipid types. However, in virus-infected rabbits fed cholesterol for 6 weeks, cholesterol ester (64.9 \pm $7.8 \%$ of total lipid) was the dominant lipid type.

\section{Rabbits were Infected with BHV-4}

$\mathrm{BHV}-4$ infection in rabbits was detected by cell culture method. Typical cytopathic effect (CPE) was observed 3 days after inoculation of bovine arterial endothelial (BAE) cell cultures with the splenic homogenates from all the virus-infected rabbits, whereas no CPE was detected 3 to 7 days after inoculation of BAE cell cultures with the splenic homogenates from the mockinfected rabbits.

\section{Detection of BHV-4 DNA by PCR}

Polymerase chain reaction (PCR) and liquid hybridization techniques were used to detect the presence of
BHV-4 DNA in various organ samples of the rabbits. For the sensitivity studies, BHV-4 DNA $\left(10^{5}\right.$ copies $\left./ \mu \mathrm{l}\right)$ was serially diluted and coamplified with internal control. The PCR product resulting from the amplification of BHV-4 genome was $271 \mathrm{bp}$ in length, while the product of internal control was $192 \mathrm{bp}$, as shown in the results of liquid hybridization (Fig. 5). A distinct positive band could be detected at approximately 10 copies of BHV-4 virion of the starting material (Fig. 5, lane 5). No specific amplification was detected in the reaction control (Fig. 5, lane 10).

Table 2 summarizes the results of BHV-4 DNA detection in the aortic sections and tissue samples by PCR and liquid hybridization. BHV-4 DNA was detected in almost all tissue homogenates, including liver, kidney, lung, heart, and spleen in infected rabbits. In thoracic and abdominal aortic sections, the positive rates were $16 / 24$ and $12 / 24$, respectively (Table 2). No positive PCR results were found in the mock-infected rabbits. The results of BHV-4 DNA detection in peripheral blood mononuclear cells (PBMC) are given in Table 3. During the experimental period, viral DNA was continuously detected in PBMC of most infected rabbits. Mock-infected rabbits were consistently negative in all PCR detection. 


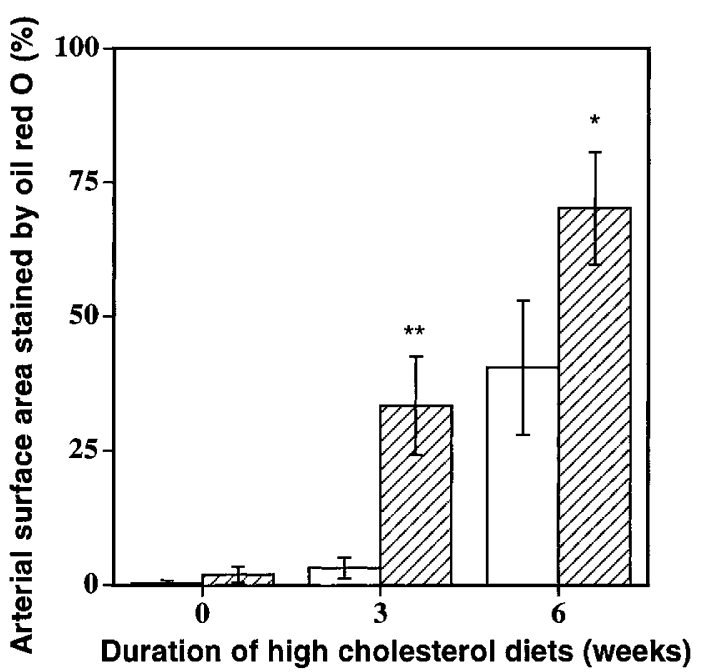

\section{Figure 4.}

Morphometric measurement of the area of thoracic aorta covered by lipid deposits. The fatty streak lesions in the aorta were revealed by oil red 0 stain. The image of the oil red 0 -stained areas viewed from the internal surface of the aorta was scanned and analyzed with a Bio-Imaging analyzer (Fuji, Tokyo, Japan) with a computer program MacBAS, v. 2.4. The size of atherosclerotic lesions is expressed as the percentage of stained area to the whole aortic surface. Open bars: Mock-infected rabbits. Hatched bars: BHV-4-infected rabbits. Error bars represent SD $\left({ }^{* *}\right): p<0.001 ;\left({ }^{*}\right): p<0.01$ with respect to the mock-infected group, by unpaired Student's $t$ test.

\section{Discussion}

In this study, we have shown that the rabbits are susceptible to infection with BHV-4. Evidence for establishment of infection includes recovery of BHV-4 by coculture of splenic homogenates with BAE cell cultures, detection of the presence of viral DNA with coamplified internal control by PCR, and liquid hybridization in various tissue samples, aortic sections, and PBMC. Therefore, we conclude that BHV-4 can establish a chronic nonsymptomatic infection in rabbits. Since BHV-4 can propagate rapidly in endothelial cell cultures (Lin et al, 1997), we suspect that it may play some role in atherogenesis. The effects of viral infection on the atherosclerotic process seemed to be more prominent in the early stage of lesion development, judging from observations of lesion size at 3 and 6 weeks after the animals were fed a high-cholesterol diet. In another set of experiments, no enhancement of arterial lesions was observed 3 weeks after inoculation of the virus when the 3-week cholesterol diet was started immediately after viral infection (TM Lin, MJ Jiang, GY Shi, and HL Wu, unpublished data, 2000). This result suggests that the synergy between viral infection and hypercholesterolemia requires an induction period. In the induction period, the virus may cause a chronic or subclinical infection in the blood vessels and damage the endothelial cells, leading to a chronic inflammation reaction. Once the damage occurs, cholesterol accumulation will be accelerated and atherosclerosis becomes more prominent (Ross, 1993). This observation is consistent with the hypothesis that many risk factors, such as hypercholesterolemia, may contribute to the acceleration of the ath- erosclerotic process once a lesion in the blood vessel is induced by a viral infection (Melnick et al, 1995).

It is interesting to note that BHV-4 infection promotes a shift of the major lipid type in the thoracic aortas from triacylglyceride to cholesterol esters following cholesterol feeding. A trend was clearly demonstrated by comparing the four experimental groups. In the mock-infected group fed cholesterol for 3 weeks, triacylglyceride was the single major lipid type, whereas cholesterol esters were the dominant type in the virus-infected group fed cholesterol for 6 weeks. In between, the virus-infected group fed cholesterol for 3 weeks exhibited a lipid distribution pattern similar to that of mock-infected group fed cholesterol for 6 weeks. Although both groups exhibited a marked increase in cholesterol esters and triacylglyceride compared with the mock-infected group with 3-week cholesterol feeding, they also showed great standard deviation in triacylglyceride levels, reflecting individual differences in responding to the given insults. The result agrees with previous studies showing that cholesterol ester accumulation in cultured smooth muscle cells was stimulated by the infection of human herpes simplex virus type 1 (Hajjar et al, 1986; Hajjar et al, 1987). It is also noteworthy that the lipid composition of aortic lesions after virus infection and 6-week cholesterol feeding exhibited a striking similarity to those reported in the type II lesions of human atherosclerosis (Geer and Malcom, 1965; Insull and Bartsch, 1966). A similar lipid composition was detected in rabbits fed a diet lower in cholesterol for a much longer period (Schwenk and Stevens, 1960; Zilversmit et al, 1961). Therefore, BHV-4 infection appears to facilitate the progression of atherosclerosis, making the short-period $2 \%$ cholesterol diet in rabbits a more representative animal model for studying the development of early atherosclerotic lesions.

In general, the PCR technique is a sensitive method for detecting viral nucleic acids. The procedures we adapted for BHV-4 DNA detection by PCR coamplification with internal control proved to be effective in detecting amplification inhibition. The liquid hybridization could provide a highly specific and sensitive method in BHV-4 DNA detection. The high degree of sensitivity of PCR allowed the detection of approximately 10 viral DNA copies (Fig. 5). In this study, the direct demonstration of viral nucleic acid in multiple organs, including liver, heart, kidney, lung, and spleen, 6 weeks after virus infection, is consistent with previous results (Naeem et al, 1991; Egyed et al, 1996; Egyed and Bartha, 1998). A lower ratio of viral DNA detection in aortic sections than in tissue homogenates was probably caused by the limited amount of aortic material available in the detection. BHV-4 DNA was detected in PBMC of the virus-infected rabbits with a decrease of positive PCR ratio after week 3 postinfection (Table 3). It is possible that at this stage some of the virus-infecting PBMC were destroyed by immune response.

The pathogenesis of BHV-4 has not been well established. Latent infection of BHV-4 in cattle is common. Splenic macrophages have been shown to 
Table 1. Lipid Composition of Thoracic Aorta Segments ${ }^{a}$

\begin{tabular}{|c|c|c|c|c|}
\hline \multirow{2}{*}{$\begin{array}{l}\text { High-cholesterol diet } \\
\text { feeding time }\end{array}$} & \multicolumn{2}{|c|}{ Mock-infected rabbit } & \multicolumn{2}{|c|}{ BHV-4 infected rabbits } \\
\hline & 3 weeks $(n=3)$ & 6 weeks $(n=3)$ & 3 weeks $(n=4)$ & 6 weeks $(n=4)$ \\
\hline Total lipid & $4.1 \pm 0.8$ & $19.8 \pm 4.5$ & $19.9 \pm 12.0$ & $42.0 \pm 6.8^{*}$ \\
\hline Total cholesterol & $0.4 \pm 0.2$ & $5.3 \pm 4.1$ & $3.6 \pm 1.7^{*}$ & $24.2 \pm 6.8^{*}$ \\
\hline Cholesterol ester & $0.8 \pm 1.1$ & $4.7 \pm 1.8$ & $4.4 \pm 2.2$ & $27.2 \pm 5.4^{*}$ \\
\hline Triacylglyceride & $1.5 \pm 0.9$ & $5.8 \pm 6.6$ & $6.8 \pm 9.9$ & $5.7 \pm 6.0$ \\
\hline
\end{tabular}

${ }^{a}$ Values are expressed as $\mathrm{mg} / \mathrm{g}$ wet tissue, mean \pm standard deviation, where $n$ is the number of assayed rabbits. All analyses were performed using unpaired Student's $t$ test.

${ }^{*}$ BHV-4 infected vs. mock-infected $(p<0.05)$.

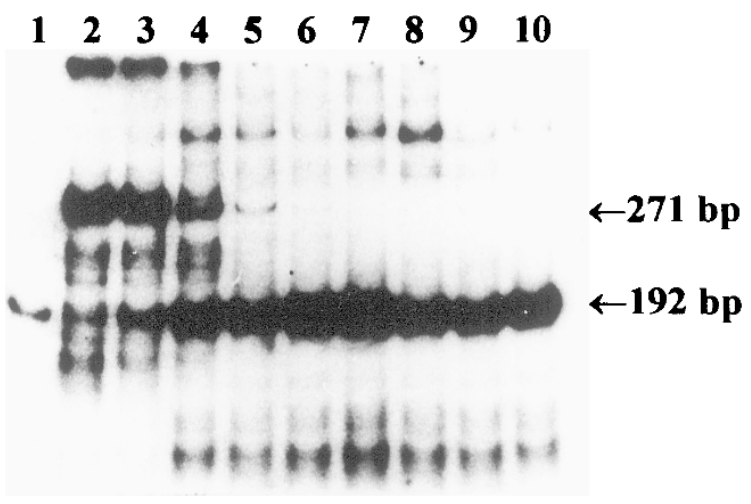

Figure 5.

Autoradiogram showing BHV-4 polymerase chain reaction (PCR) products hybridized with a ${ }^{32} \mathrm{P}-5^{\prime}$-end-labeled specific probe. Lanes 1 to 9 represent amplifications with serial 10-fold dilutions of purified BHV-4 DNA from $10^{5}$ to $10^{-3}$ copies coamplified with 50 copies of internal control DNA, respectively. Lane 10 is a negative control. Lane 5 contains approximately 10 copies of BHV-4 DNA. A product of BHV-4 appears at $271 \mathrm{bp}$ and the product of internal control appears at $192 \mathrm{bp}$.

Table 2. Detection of BHV-4 DNA by PCR in Various Tissue Specimens and Aortic Sections of the Experimental Rabbits

\begin{tabular}{lcc}
\hline \multicolumn{1}{c}{ Samples } & Virus-infected $^{a}$ & Mock-infected $^{a}$ \\
\hline Lung & $23 / 24$ & $0 / 16$ \\
Spleen & $24 / 24$ & $0 / 16$ \\
Liver & $24 / 24$ & $0 / 16$ \\
Heart & $24 / 24$ & $0 / 16$ \\
Kidney & $24 / 24$ & $0 / 16$ \\
Thoracic aorta & $16 / 24$ & $0 / 16$ \\
Abdominal aorta & $12 / 24$ & $0 / 16$ \\
\hline
\end{tabular}

${ }^{a}$ Values indicate number of rabbits yielding positive result/total number of rabbits tested. All the specimens were collected on postinfection Week 6 . One micrograms of tissue DNA and 0.1 to $0.5 \mu \mathrm{g}$ of aortic section DNA were used for the detection.

be the main reservoir of BHV-4 infection in cattle and rabbits (Osorio et al, 1985; Lopez et al, 1996). In our study, we demonstrated that BHV-4 DNA could be detected in the aortic sections. Therefore, the possibility of latency and reactivation of BHV-4 in the vascular wall should be investigated further to see how infection and reactivation of latent virus affect atherogenesis and its progress. The biological characteristics and pathogenesis of BHV-4 are similar to
Table 3. Detection of BHV-4 DNA by PCR in PBMCs of the Experimental Rabbits

\begin{tabular}{ccc}
\hline $\begin{array}{c}\text { Postinfection } \\
\text { (week) }\end{array}$ & Virus-infected $^{a}$ & Mock-infected $^{a}$ \\
\hline-1 & $0 / 24$ & $0 / 16$ \\
0 & $0 / 24$ & $0 / 15$ \\
1 & $22 / 24$ & $0 / 16$ \\
2 & $20 / 22$ & $0 / 16$ \\
3 & $18 / 22$ & $0 / 14$ \\
4 & $16 / 21$ & $0 / 15$ \\
5 & $16 / 23$ & $0 / 14$ \\
6 & $15 / 22$ & $0 / 14$ \\
\hline
\end{tabular}

\footnotetext{
${ }^{a}$ Values indicate number of rabbits yielding positive result/total number of
} rabbits tested. The amount of DNA used for the detection was 0.1 to $0.5 \mu \mathrm{g}$.

human CMV. Therefore, the rabbit model of atherosclerosis with BHV-4 infection could be a suitable and useful model for studying the pathogenic role of CMV in atherosclerosis. In conclusion, we have demonstrated that BHV-4 infection accelerates the hypercholesterolemia-induced atherosclerosis in the rabbits fed a high-cholesterol diet. Detection of the presence of viral DNA in the thoracic aorta suggests a pathogenic role of BHV-4 infection in atherosclerosis.

\section{Materials and Methods \\ Animals}

Forty pathogen-free New Zealand White male rabbits 2 to 3 months old, weighing 2.5 to $3 \mathrm{~kg}$, were purchased from Taiwan Livestock Research Institute, and housed individually in the animal center of National Cheng Kung University, Medical College, Tainan, Taiwan. Animals were determined to be free of BHV-4 infection by immunofluorescent antibody screening.

\section{Virus Stock}

The BHV-4, DN599 (Cat. No. VR 631), American reference strain, was obtained from the American Type Culture Collection (Rockville, Maryland). To prepare the virus stock, DN599 was cultured in BAE cells. BAE cells were isolated from bovine carotid arteries as described previously (Morita et al, 1984; Chang et al, 1991; Lin et al, 1997) and maintained in Dulbecco's modified Eagle's medium (DMEM; Gibco BRL, Gaithersburg, Maryland) containing $10 \%$ heat-inactivated 
fetal bovine serum (FBS; Gibco). The virus induced typical CPE in BAE cells 5 days after infection and was then harvested from cultured cells by freezing and thawing. The infected medium was centrifuged for 10 minutes at $3,000 \mathrm{rpm}$ to remove cell debris. The supernatants containing virus with a titer of $4 \times 10^{10}$ tissue culture infectious dose $\left(\mathrm{TCID}_{50}\right)$ per milliliter were stored at $-80^{\circ} \mathrm{C}$ until use.

\section{Experimental Groups}

Forty rabbits of comparable size were randomly assigned to six groups. All rabbits were initially fed a standard chow diet (Purina Mills, Richmond, Indiana) before the experiment. Rabbits in Groups 1, 2, and 3 were inoculated iv with $4 \times 10^{8} \mathrm{TCID}_{50}$ of $\mathrm{BHV}-4$ in 50 $\mathrm{ml}$ normal saline by continuous infusion of the diluted virus suspension at a fixed rate of $3 \mathrm{ml} /$ minute. Groups 4,5 , and 6 were inoculated with normal saline as controls at the same infusion rate. Infected and uninfected rabbits were housed separately to prevent cross-infection, but all other conditions were identical. Each rabbit was fed a daily diet of $110 \mathrm{~g}$ of a regular or high-cholesterol chow. Groups $1(n=8)$ and $4(n=6)$ were fed a regular diet for 45 days. Groups $2(n=8)$ and $5(n=5)$ were fed a regular diet for 24 days, then a high-cholesterol diet (2\% cholesterol) for 21 days. Groups $3(n=8)$ and $6(n=5)$ were fed a regular diet for 3 days, then a $2 \%$ cholesterol diet for 42 days.

\section{Sample Collection}

Weekly blood samples were collected from rabbits in EDTA tubes. Plasma was separated promptly by centrifugation at 2,500 rpm for 15 minutes and stored at $-70^{\circ} \mathrm{C}$ until analysis. Buffy coats were harvested and resuspended in RPMI-1640 (Gibco) without sera. PBMC were isolated by centrifugation on FicollHypaque (Pharmacia, Uppsala, Sweden), hypotonically lysed of contaminated erythrocytes, resuspended in lysis buffer (50 mm Tris- $\mathrm{HCl}, \mathrm{pH} 8.0$, containing $500 \mathrm{~mm} \mathrm{NaCl}, 125 \mathrm{~mm}$ EDTA, and 2.5\% SDS), and frozen at $-20^{\circ} \mathrm{C}$.

\section{Plasma Cholesterol Analysis}

The levels of plasma cholesterol were determined with a commercial kit (Daiichi, Tokyo, Japan), according to the manufacturer's recommendation, with a Combas Mira automated analyzer (Roche Diagnostica, Basel, Switzerland).

\section{Evaluation of Atherosclerosis}

Rabbits were anesthetized by intravenous injection of 35 to $40 \mathrm{mg} / \mathrm{kg}$ sodium pentobarbital. The thoracic aorta, both ascending and descending segments, and the abdominal aorta from the diaphragm to the iliac bifurcation were removed, stripped of adipose tissue and adventitia, rinsed with ice-cold phosphatebuffered saline (PBS), and fixed by immersing in $4 \%$ buffered paraformaldehyde. The fixed thoracic aorta was washed three times with PBS, immersed in 50\% isopropyl alcohol for 10 minutes, and stained with oil red $\mathrm{O}$ for 10 minutes to reveal fatty deposits. After thorough washing with $10 \%$ isopropyl alcohol, the aorta was opened and the luminal surface was examined for grossly visible atherosclerotic plaques. Morphometric assessment of the percentages of the total thoracic aorta covered by lipid deposits was determined by computerized planimetry. The image of the oil red O-stained areas viewed from the internal surface of the aorta was scanned and analyzed with a Bio-Imaging analyzer (Fuji) with a computer program, MacBAS, V. 2.4. The size of atherosclerotic lesions is expressed as the percentage of the stained area to the whole aortic surface. To compare the relative area of lipid deposition in the virus-inoculated groups versus their respective mock-inoculated control groups, an unpaired $t$ test was performed. For microscopic examination, segments of the oil red O-stained aorta were embedded in paraffin. Sections (8 to $10 \mu \mathrm{m}$ thickness) of the blood vessels from the paraffin block were stained with hematoxylin-eosin for light microscopic examination.

The oil red O-stained thoracic aorta segments were cleaned of gross adventitial tissue and blotted dry. The lipids were extracted with a mixture of chloroform and methanol $(2: 1, v / v)$ for total lipids according to a modified method of Folch et al (1957). The extracts were dried under a stream of nitrogen and resuspended in deuterated chloroform for ${ }^{1} \mathrm{H}-\mathrm{NMR}$ spectroscopic measurements.

NMR experiments were performed at room temperature on a Burker Avance 500 FT-NMR spectrometer. The signal intensity at $0.68 \mathrm{ppm}$ of free and esterified cholesterol was used to determine total cholesterol. The cholesterol esters were determined as cholesteryl oleate, which was estimated by the signal intensity of $\mathrm{H}-3 \alpha$ of esterified cholesterol at $4.60 \mathrm{ppm}$. Triacylglycerol was determined as triolein by the signal intensities at 4.15 and $4.30 \mathrm{ppm}$, representing chemical shifts of protons attached to $\mathrm{C}-1 / \mathrm{C}-3$ of glycerol moiety.

\section{Isolation of Virus from Rabbit Spleen}

The BAE cells were inoculated with homogenates of fresh rabbit spleens in DMEM containing 10\% FBS and incubated overnight. After washing with PBS three times, the cell culture was replenished with fresh medium and incubated at $37^{\circ} \mathrm{C}$. The culture was examined daily for 1 week for CPE.

\section{Sample Preparation for PCR}

Tissue samples (kidney, spleen, lung, heart, and liver) were frozen at $-70^{\circ} \mathrm{C}$ after necropsy. To extract total DNA, frozen tissues were dissected into $3 \times 3-\mathrm{mm}$ pieces and were triturated in $1 \mathrm{ml}$ buffer containing 20 mM Tris-HCl (pH 8.0), 5 mm EDTA, 2\% SDS, and 2 $\mathrm{mg} / \mathrm{ml}$ RNAse A. Ten 6- $\mu \mathrm{m}$-thick sections were cut from the paraffin embedded aortas under stringent conditions to avoid cross-contamination. Sections were then deparaffinized in xylene and rehydrated with graded ethanol. The dried sections were lysed by 
$0.5 \mathrm{ml}$ lysis buffer containing $10 \mathrm{~mm}$ Tris- $\mathrm{HCl}(\mathrm{pH} 8.0)$, $10 \mathrm{~mm}$ EDTA, $150 \mathrm{~mm} \mathrm{NaCl}$, and 2.5\% SDS.

The tissue and aortic section samples were then digested with $500 \mu \mathrm{g} / \mathrm{ml}$ of proteinase K (BoehringerMannheim Biochemica, Mannheim, Germany) at $50^{\circ} \mathrm{C}$ overnight, and extracted sequentially with phenol, phenol:chloroform (1:1), and chloroform:isoamyl ethanol (24:1). The aqueous phase was precipitated with one tenth of $3 \mathrm{~m}$ ammonium acetate $(\mathrm{pH} 5.2)$, one hundredth $10 \%$ glycogen, and 2 volumes of absolute ethanol. DNA pellets were air-dried and resuspended in $50 \mu$ l of Tris buffer ( $\mathrm{pH}$ 8.0). The DNA concentration was determined by absorbance at $260 \mathrm{~nm}$. BHV-4 DNA was extracted and purified from the virus as described previously (Almendral et al, 1984) and was used as a positive control. An extraction negative control of U937 cells was included in every three extractions to detect cross-contamination of samples. Tissue processing, DNA extraction, and PCR amplification were performed in separate rooms.

\section{PCR and Liquid Hybridization}

A pair of PCR primers were prepared from the sequences of the nonconserved region $E$ of $B H V-4$ (BHV4REGE), based on the GenBank EMBL data bank (accession number AC Z46385). The sequences of the selected primers are: P1: 5'TGAGACATCTGGGAGTGCTTC (position 6153-6173), and P2: 5'CTCCTTCACTTCTGCCAGTG (position 6423-6404). The sequence of the hybridization probe was: GCTCTGGAGTCACTCTGTCTGTGTGTGATG (position 62696298). To create the coamplified internal control, we selected another pair of primers as follows. C1: 5'TGAGACATCTGGGAGTGCTTCTGCCAGGGTCACTTGC (position 6153-6173, 6207-6225), and C2: 5'CTCCTTCACTTCTGCCAGTGTTACCTGGGCATCCCCACATTC (position 6423-6404, 6357-6336). The BHV-4 coamplified internal control was synthesized by two steps of PCR to make a deletion PCR product of 192 base pairs (bp). However, it can be amplified with the same primers (P1 and P2) and can be detected by the same probes. The probe was 5 '-endlabeled with $\gamma$ - ${ }^{32}$ P-ATP (Amersham, Buckinghamshire, United Kingdom) by T4 kinase (Promega, Madison, Wisconsin) according to manufacturer specifications. The incorporated ${ }^{32} \mathrm{P}$-radiolabeled was separated from unincorporated label by chromatography on a Sephadex G-25 spin column (BoehringerMannheim). The specific activity was $1 \times 10^{6} \mathrm{cpm} / \mathrm{mg}$.

The PCR amplification was carried out in 50- $\mu$ l reaction mixtures containing $5 \mu \mathrm{l}$ of $10 \times \mathrm{PCR}$ buffer (100 mm Tris, pH 9.0, $500 \mathrm{~mm} \mathrm{KCl,} 1$ mg of bovine serum albumin per $\mathrm{ml}$ ), $200 \mu \mathrm{M}$ each deoxynucleotide triphosphate (dNTP; Boehringer-Mannheim), $100 \mathrm{~nm}$ of each primer, $1 \mathrm{U}$ of Taq DNA polymerase (PerkinElmer, Branchburg, New Jersey), $1.5 \mathrm{~mm} \mathrm{MgCl}_{2}$, and 5 $\mu$ l glycerol. To detect any inhibition in the sample, 50 copies of internal control were added to each reaction mixture to monitor for inhibition of the reaction by the DNA preparation (Cone et al, 1992). Fifty copies of internal control DNA also did not competitively inhibit the amplification of the original target DNA. The DNA amplification included 35 cycles of denaturation at $94^{\circ} \mathrm{C}$ for 1 minute, annealing at $55^{\circ} \mathrm{C}$ for 1.5 minutes, and synthesis at $72^{\circ} \mathrm{C}$ for 2 minutes, which was performed with the Perkin-Elmer Cetus DNA Thermal Cycler.

The PCR products were detected by liquid hybridization. Seven microliters of PCR products were added to $50 \mathrm{~mm}$ Tris ( $\mathrm{pH} 8.0$ ) buffer containing $1.2 \mathrm{M}$ $\mathrm{NaCl}, 100 \mu \mathrm{M}$ dNTP, $60 \%$ formamide, and $10^{5} \mathrm{cpm}$ of ${ }^{32} \mathrm{P}$-labeled probe per reaction in a total volume of 25 $\mu \mathrm{l}$. The mixtures were hybridized by heating to $97^{\circ} \mathrm{C}$ for 5 minutes and cooling to room temperature over 15 minutes. Five microliters of each hybridized reaction mixture was subjected to electrophoresis in a $8 \%$ acrylamide gel with TBE buffer $(0.089 \mathrm{M}$ Tris, $0.089 \mathrm{M}$ boric acid, 2 mm EDTA). The gels were autoradiographed with Kodak BioMax film (Rochester, New York) for 18 hours.

\section{Acknowledgements}

The authors wish to thank Dr. Ming-Shi Shiao, Department of Medical Research and Education, Veterans General Hospital, Taipei, Taiwan, ROC, for assistance with the major lipid determination of the thoracic aorta segments by ${ }^{1} \mathrm{H}$-nuclear magnetic resonance.

\section{References}

Adam E, Melnick JL, Probtsfield JL, Petrie BL, Burek J, Bailey KR, McCollum CH, and DeBakey ME (1987). High levels of cytomegalovirus antibody in patients requiring vascular surgery for atherosclerosis. Lancet 2:291-293.

Almendral JM, Blasco R, Ley V, Beloso A, Talavera A, and Vinuela $E$ (1984). Restriction site map of African swine fever virus DNA. Virology 133:258-270.

Bublot M, Lomonte P, Lequarre AS, Albrecht JC, Nicholas J, Fleckenstein B, Pastoret PP, and Thiry E (1992). Genetic relationships between bovine herpesvirus 4 and the gammaherpesviruses Epstein-Barr virus and herpesvirus Saimiri. Virology 190:654-665.

Campbell JH and Campbell GR (1994). Cell biology of atherosclerosis. J Hypertension 12(Suppl 10):S129-S132.

Castrucci G, Frigeri F, Ferrari M, Di Luca D, and Traldi V (1991). A study of some biologic properties of bovid herpesvirus-4. Comp Immun Microbiol Infect Dis 14:197207.

Chang WC, Chen SH, Wu HL, Shi GY, Murota S, and Morita I (1991). Cytoprotective effect of reduced glutathione in arsenical-induced endothelial cell injury. Toxicology 69:101110.

Cone RW, Hobson AC, and Huang MLW (1992). Coamplified positive control detects inhibition of polymerase chain reactions. J Clin Microbiol 30:3185-3189.

Egyed L, Ballagi-Pordany A, Bartha A, and Belak S (1996). Studies of in vivo distribution of bovine herpesvirus type 4 in the natural host. J Clin Microbiol 34:1091-1095.

Egyed L and Bartha A (1998). PCR studies on the potential sites for latency of BHV-4 in calves. Vet Res Commun 22:209-216. 
Fabricant CG, Fabricant J, Litrenta MM, and Minick CR (1978). Virus-induced atherosclerosis. J Exp Med 148:335340.

Folch J, Lees M, and Stanley GHS (1957). A simple method for the isolation and purification of total lipids from animal tissues. J Biol Chem 226:497-509.

Geer JC and Malcom GT (1965). Cholesterol ester fatty acid composition of human aorta fatty streaks and normal intima. Exp Mol Pathol 4:500-507.

Hajjar DP, Fabricant CG, Minick CR, and Fabricant J (1986). Virus-induced atherosclerosis: Herpesvirus infection alters aortic cholesterol metabolism and accumulation. Am J Pathol 122:62-70.

Hajjar DP, Pomerantz KB, Falcone DJ, Weksler BB, and Grant AJ (1987). Herpes simplex virus infection in human arterial cells: Implications in arteriosclerosis. J Clin Invest 80:1317-1321.

Insull WJ and Bartsch GE (1966). Cholesterol, triglyceride, and phospholipid content of intima, media, and atherosclerotic fatty streak in human thoracic aorta. J Clin Invest 45:513-523.

Kannel WB, McGee D, and Gordon T (1976). A general cardiovascular risk profile: The Framingham study. Epidemiology 38:46-51.

Lin TM, Shi GY, Tsai CF, Su HJ, Guo YLL, and Wu HL (1997). Susceptibility of endothelial cells to bovine herpesvirus type 4 (BHV-4). J Virol Meth 63:219-225.

Lopez OJ, Galeota JA, and Osorio FA (1996). Bovine herpesvirus type-4 (BHV-4) persistently infects cells of the marginal zone of spleen in cattle. Microb Pathogen 21:47-58.

Ludwig H (1983). Bovine herpesviruses. In: Roizman B, editor. The herpesviruses. New York: Plenum Press, pp 135-214.

Massy ZA and Keane WF (1996). Pathogenesis of atherosclerosis. Sem Nephrol 16:12-20.

Melnick JL, Adam E, and Debakey ME (1993). Cytomegalovirus and atherosclerosis. Eur Heart J 14:30-38.

Melnick JL, Adam E, and DeBakey ME (1995). Cytomegalovirus and atherosclerosis. BioEssays 17:899-903.

Melnick JL, Petrie BL, Dreesman GR, Burek J, McCollum CH, and DeBakey ME (1983). Cytomegalovirus antigen within human arterial smooth muscle cells. Lancet 2:644-647.

Minick CR, Fabricant CG, Fabricant J, and Litrenta MM (1979). Atheroarteriosclerosis induced by infection with a herpesvirus. Am J Pathol 96:673-706.

Morita I, Kanayasu T, and Murota S (1984). Kallikrein stimulates prostacyclin production in bovine vascular endothelial cells. Biochim Biophys Acta 792:304-309.

Naeem K, Caywood DD, Werdin RE, and Goyal SM (1990). Evaluation of pregnant rabbits as a laboratory model for bovid herpesvirus-4 infection. Am J Vet Res 51:640-644.

Naeem K, Murtaugh MP, and Goyal SM (1991). Tissue distribution of bovid herpesvirus- 4 inoculated rabbits and its detection by DNA hybridization and polymerase chain reaction. Arch Virol 119:239-255.
Nicholson AC and Hajjar DP (1998). Herpesvirus in atherosclerosis and thrombosis: etiologic agents or ubiquitous bystanders? Arterioscler Thromb Vas Biol 18:339-348.

Nieto FJ, Adam E, Sorlie P, Farzadegan H, Melnick JL, Comstock GW, and Szklo M (1996). Cohort study of cytomegalovirus infection as a risk factor for carotid intimalmedial thickening, a measure of subclinical atherosclerosis. Circulation 94:922-927.

Osorio FA and Reed DE (1983). Experimental inoculation of cattle with bovine herpesvirus-4: evidence for a lymphoidassociated persistent infection. Am J Vet Res 44:975-780.

Osorio FA, Reed DE, and Rock DL (1982). Experimental infection of rabbits with bovine herpesvirus-4: Acute and persistent infection. Vet Microbiol 7:503-513.

Osorio FA, Rock DL, and Reed DE (1985). Studies on the pathogenesis of a bovine cytomegalo-like virus in an experimental host. J Gen Virol 66:1941-1951.

Persoons MC, Daemen MJ, Bruning JH, and Bruggeman CA (1994). Active cytomegalovirus infection of arterial smooth muscle cells in immunocompromised rats: A clue to herpesvirus-associated atherogenesis? Cir Res 75:214-220.

Petrie BL, Melnick JL, Adam E, Burek J, McCollum CH, and DeBakey ME (1987). Nucleic acid sequences of cytomegalovirus in cells cultured from human arterial tissue. J Infect Dis 155:158-159.

Ross $R$ (1986). The pathogenesis of atherosclerosis. N Engl J Med 314:488-500.

Ross R (1993). The pathogenesis of atherosclerosis: A perspective for the 1990s. Nature 362:801-809.

Ross R and Glomset JA (1976). The pathogenesis of atherosclerosis. N Engl J Med 295:369-377, 420-425.

Schwenk E and Stevens DF (1960). Deposition of cholesterol in experimental rabbit atherosclerosis. Proc Soc Exp Biol Med 103:614-617.

Span AHM, Grauls G, Bosman F, van Boven CPA, and Bruggeman CA (1992). Cytomegalovirus infection induces vascular injury in the rat. Atherosclerosis 93:41-52.

Staczek J (1990). Animal cytomegaloviruses. Microbiol Rev 54:247-265.

Storz J, Ehlers B, Todd WJ, and Ludwig H (1984). Bovine cytomegaloviruses: Identification and differential properties. J Gen Virol 65:697-706.

Thiry E, Bublot M, Dubuisson J, and Pastoret PP (1989). Bovine herpesvirus-4 (BHV-4) infections in cattle. In: Wittmann G, editor. Herpesvirus diseases of cattle, horses, and pigs. Boston: Kluwer Press, pp 96-115.

Zilversmit DB, Sweeley CC, and Newman HA (1961). Fatty acid composition of serum and aortic intimal lipids in rabbits fed low- and high-cholesterol diets. Circ Res 9:235-241. 